\title{
A Novel Active Snubber for High-Power Boost Converters
}

\author{
Milan M. Jovanović, Senior Member, IEEE, and Yungtaek Jang, Member, IEEE
}

\begin{abstract}
A technique which improves the performance of the boost converter by reducing the reverse-recovery-related losses in the boost switch and rectifier with an active snubber that is implemented with a minimum number of components is presented. This minimum-component-count snubber consists of a snubber inductor, an auxiliary switch, and a rectifier. The proposed technique reduces the reverse-recovery-related losses by controlling the turn-off $\mathrm{di} / \mathrm{dt}$ rate of the rectifier current with the snubber inductor connected in series with the boost switch and rectifier. The voltage and current stresses of the components in the proposed active-snubber boost converter are similar to those in its conventional "hard-switched" counterpart.
\end{abstract}

Index Terms-Active snubber, boost converter, power factor correction, reverse recovery loss, zero voltage switching.

\section{INTRODUCTION}

A $\mathrm{T}$ HIGHER power levels, the continuous-conduction-mode boost converter is the preferred topology for implementing a front end with active input-current shaping. As a result, in recent years, significant efforts have been made on improving the performance of high-power boost converters. The majority of these development efforts have been focused on reducing the adverse effects of the reverse-recovery characteristic of the boost rectifier on the conversion efficiency and electromagnetic compatibility (EMC) [1].

Generally, the reduction of the reverse-recovery-related losses and EMC problems requires that the boost rectifier be "softly" switched off by controlling the turn-off rate of its current. For a majority of today's rectifiers the optimal turn-off $\mathrm{di} / \mathrm{dt}$ rate is below $100 \mathrm{~A} / \mu \mathrm{S}$.

So far, a number of soft-switched boost converters and their variations have been proposed [2]-[10]. All of them use additional components to form an active snubber [2]-[7], or a passive lossless snubber [8]-[10] circuit that controls the turn-off $\mathrm{di} / \mathrm{dt}$ rate of the boost rectifier. Generally, the active-snubber approaches employ an auxiliary active switch with a few passive components such as inductors, capacitors, and rectifiers, whereas the passive-snubber approaches use only passive components.

The main feature of the active approaches introduced in [2]-[7] is that besides soft switching of the boost rectifier they also offer the zero-voltage switching (ZVS) of the boost switch. In addition, the approaches described in [4]-[7] offer soft switching of the auxiliary switch. Specifically, in the

\footnotetext{
Manuscript received February 2, 1999; revised July 22, 1999. Recommended by Associate Editor, J. Enslin.

The authors are with the Delta Products Corporation, Power Electronics Laboratory, Research Triangle Park, NC 27709 USA.

Publisher Item Identifier S 0885-8993(00)02343-7.
}

active-snubber implementation in [4], the snubber switch turns off with zero-current switching (ZCS), whereas in the implementations in [5]-[7], it turns on with ZVS. In addition, all these active approaches exhibit voltage and current stresses on the semiconductor components which are similar to those in the boost circuit without a snubber. The major downside of the active snubber approaches is a relatively large component count, as well as the need for a driver for the snubber's active switch. Moreover, the active snubbers introduced in [5]-[7] require a less-desirable, isolated (high-side) drive for the snubber switch.

Generally, the passive lossless snubbers are as effective as the active snubbers in reducing the reverse-recovery-related losses because they implement the soft switching of the boost rectifier in a similar way as the active snubbers. However, the passive snubbers do not offer ZVS of the boost switch. This does not have a significant detrimental effect on the conversion efficiency since the efficiency reduction because of the capacitive turn-on loss of the boost switch due to the absence of ZVS is typically less than $0.5 \%$. The major drawback of the passive approaches is a significantly increased voltage and/or current stress on the semiconductor components [8]-[10]. This increased stress dictates the use of higher-rated and, usually, more expensive components. Additionally, some passive-snubber implementations require a relatively large number of passive components.

In this paper, a simple active-snubber implementation for the boost power stage is proposed. The snubber is implemented with only three components and it offers both the soft switching of the boost rectifier and the snubber switch. In addition, this minimum-component-count active snubber employs a direct (non-isolated) drive for the snubber switch, and operates with overlapping gate-drive signals of the boost and snubber switches, which enhances the robustness of the circuit. The voltage and current stresses of the components in this active-snubber boost converter are similar to those in its conventional "hard-switched" counterpart. Finally, it was verified experimentally on a $1-\mathrm{kW}$, universal-input boost power stage that the proposed active snubber is effective in extending the power range of the boost converter by reducing the reverse-recovery-related losses.

\section{ANALYSIS OF OPERATION}

The circuit diagram of the boost converter which employs the new technique for reverse-recovery-loss reduction is shown in Fig. 1. The circuit in Fig. 1 uses snubber inductor $L_{S}$ connected in series with boost switch $S$ and rectifier $D$ to control the $d i / d t$ rate of the rectifier. The snubber action is controlled by auxiliary 
switch $S_{1}$ which is connected between the anode of boost rectifier $D$ and the circuit ground. The function of snubber rectifier $D_{S}$ is to clamp the voltage across main switch $S$ to the output voltage after switch $S$ is turned off.

To simplify the analysis of operation, it is assumed that the inductance of boost inductor $L$ is large so that it can be represented by constant-current source $I_{I N}$, and that the output-ripple voltage is negligible so that the voltage across the output filter capacitor can be represented by constant-voltage source $V_{O}$. Also, it is assumed that in the on-state semiconductors exhibit zero resistance, i.e., they are short circuits. However, the output capacitance of the switches and the reverse-recovery charge of the rectifiers are not neglected in this analysis. The circuit diagram of the simplified converter, as well as the reference directions for currents and voltages are shown in Fig. 2.

To further facilitate the explanation of the operation, Fig. 3 shows topological stages of the circuit in Fig. 1 during a switching cycle, whereas Fig. 4 shows the power-stage key waveforms. As can be seen from the gate-drive timing diagrams for the boost and auxiliary switches in Fig. 4, the proposed circuit operates with an overlapping gate drive of the switches, i.e., both switches conduct simultaneously.

Before main switch $S$ is turned on at $t=T_{0}$, the entire input current $I_{I N}$ flows through snubber inductor $L_{S}$ and boost rectifier $D$. At the same time, auxiliary switch $S_{1}$ is off blocking voltage $V_{O}$, whereas snubber rectifier $D_{S}$, ideally, carries no current.

After switch $S$ is turned on at $t=T_{0}$, constant voltage $V_{O}$ is applied across $L_{S}$, as shown in Fig. 3(a). As a result, inductor current $i_{L S}$ and rectifier current $i_{D}$ decreases linearly, whereas switch current $i_{S}$ increases at the same rate. The rate of the rectifier current decrease is governed by

$$
\frac{d i_{D}}{d t}=-\frac{V_{O}}{L_{S}}
$$

Since the rate of the boost rectifier current decrease is controlled by snubber inductance $L_{S}$, the rectifier's recovered charge and the associated losses can be reduced by a proper selection of the $L_{S}$ inductance. Generally, a larger inductance, which gives a lower $d i_{D} / d t$ rate, results in a more efficient reduction of the reverse-recovery-associated losses [1].

At $t=T_{1}$, when $i_{L S}$ and $i_{D}$ decrease to zero, the entire input current $I_{I N}$ flows through switch $S$, as shown in Fig. 4. Ideally, when $i_{D}$ falls to zero at $t=T_{1}$, rectifier $D$ should stop conducting. However, due to a residual stored charge, reverse-recovery current $i_{R R}$ will flow through rectifier $D$, as shown in Fig. 3(b). After rectifier $D$ recovers at $t=T_{2}$, the rectifier stops conducting, and output capacitance $C_{O S S 1}$ of switch $S_{1}$ starts discharging in a resonant fashion by current $i_{L S}$, as shown in Fig. 3(c). During this resonance, negative snubber-inductor current $i_{L S}$ increases by the amount of $V_{O} / \sqrt{L_{S} / C_{O S S 1}}$, as indicated in the $i_{L S}$ waveform in Fig. 4. After $C_{O S S 1}$ is completely discharged at $t=T_{3}$, current $i_{L S}$ which was flowing through $C_{O S S 1}$ continues to flow through antiparallel diode $D_{A P 1}$ of auxiliary switch $S_{1}$, as indicated in Fig. 3(d).

Since at $t=T_{4}$ when auxiliary switch $S_{1}$ is closed its antiparallel diode $D_{A P 1}$ is conducting, auxiliary switch $S_{1}$ always

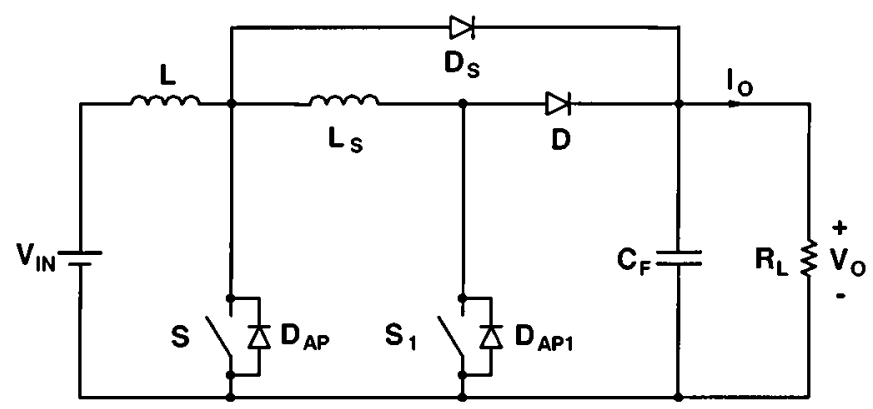

Fig. 1. Boost power stage with minimum-component-count active snubber.

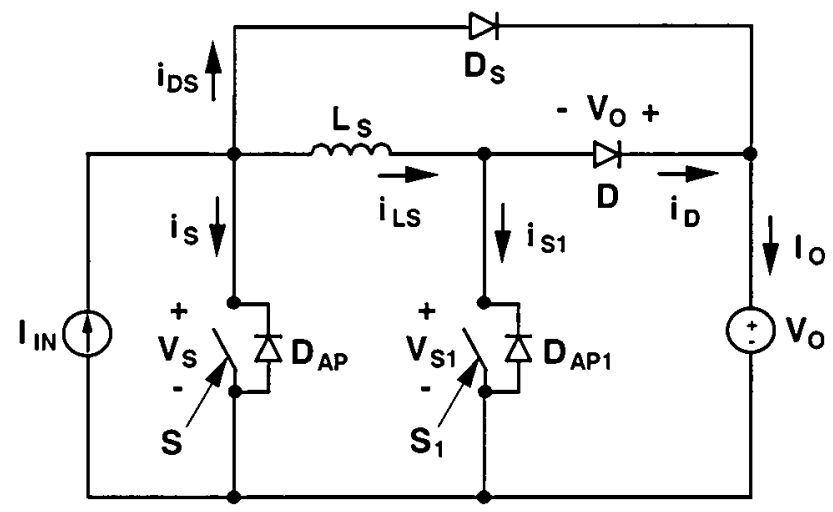

Fig. 2. Simplified circuit diagram of the proposed boost power stage showing reference directions of currents and voltages.

turns on under ZVS condition. After switch $S_{1}$ is turned on, current $i_{L S}$ continues to flow through switch $S_{1}$ instead through its antiparallel diode $D_{A P 1}$, as shown in Fig. 3(e).

After main switch $S$ is turned off at $t=T_{5}$, switch current $i_{S}$ is diverted from the switch to its output capacitance $C_{O S S}$, as shown in Fig. 3(f). As a result, voltage across switch $S, v_{S}$, increases. Since, typically, input current $I_{I N}$ is much larger than $\left|i L_{S}\right|=\mid i_{R R}+V_{O} /$ sqrt $_{S} / C_{O S S 1} \mid$, the increase of $v_{S}$ is essentially linear, as illustrated in Fig. 4 . At the same time, $i_{L S}$ starts to slowly increase from its initial negative value due to rising switch voltage $v_{S}$. When $v_{S}$ reaches $V_{O}$ at $t=T_{6}$, switch current $i_{S}$ which was charging $C_{O S S}$ is diverted to snubber rectifier $D_{S}$, as shown in Fig. 3(g). Since after $D_{S}$ starts conducting at $t=T_{6}$, constant positive voltage $V_{O}$ is applied across $L_{S}$, current $i_{L S}$ continues to increase linearly, as shown in Fig. 4. At the same time, snubber-rectifier current $i_{D S}$ decreases at the same rate because the sum of $i_{L S}$ and $i_{D S}$ is equal to the constant input current $I_{I N}$. When $i_{D S}$ reaches zero at $t=T_{7}, D_{S}$ turns off.

After $D_{S}$ stops conducting at $t=T_{7}$ the circuit can have different modes of operation depending on the time that auxiliary switch $S_{1}$ is still kept on. For optimal performance, switch $S_{1}$ should be turned off immediately after $i_{D S}$ reaches zero, as it will be discussed in the next section. When switch $S_{1}$ is turned off at $t=T_{7}$, inductor current $i_{L S}=I_{I N}$, which was flowing through switch $S_{1}$, is diverted to output capacitance $C_{O S S 1}$, as shown in Fig. 3(h). Because of a constant-current charging, $v_{S 1}$ increases linearly toward $V_{O}$, whereas $v_{D}$ decreases linearly toward zero, as illustrated in Fig. 4 . When, at $t=T_{8}, v_{S 1}$ reaches 


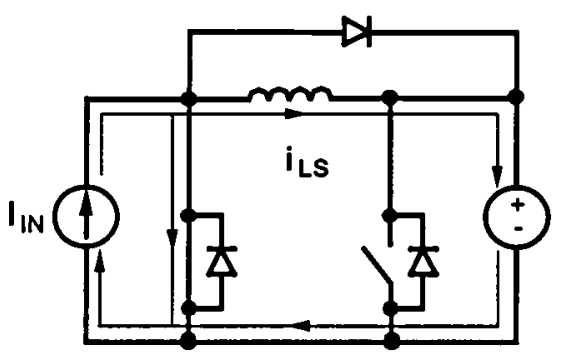

(a) $\left[T_{0}-T_{1}\right]$

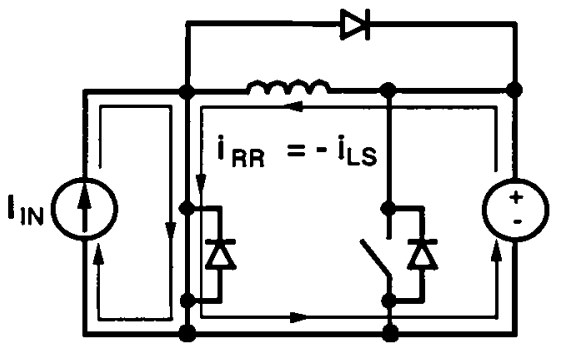

(b) $\left[T_{1}-T_{2}\right]$

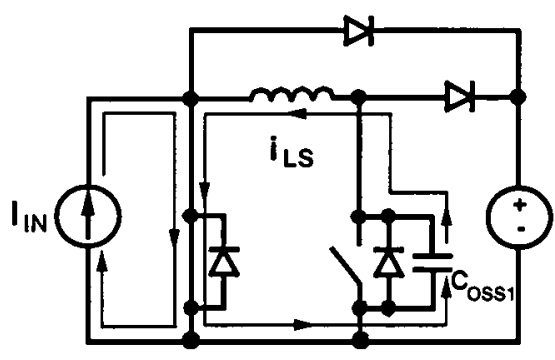

(c) $\left[T_{2} \cdot T_{3}\right]$

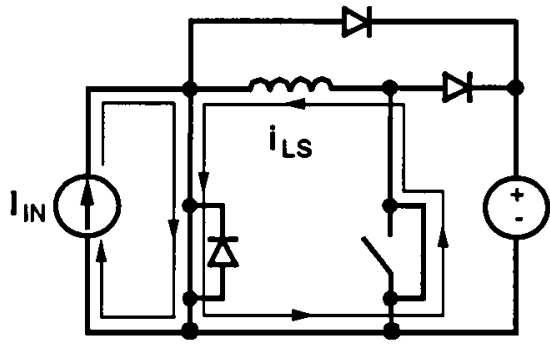

(d) $\left[T_{3}-T_{4}\right]$

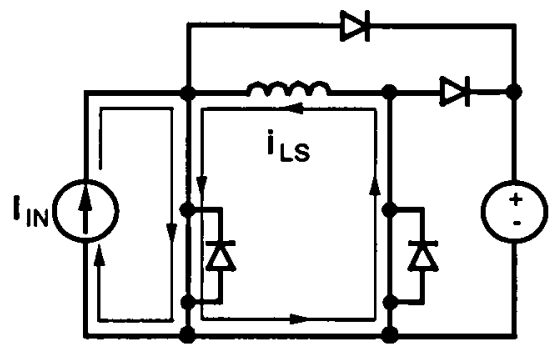

(e) $\left[T_{4}-T_{5}\right]$

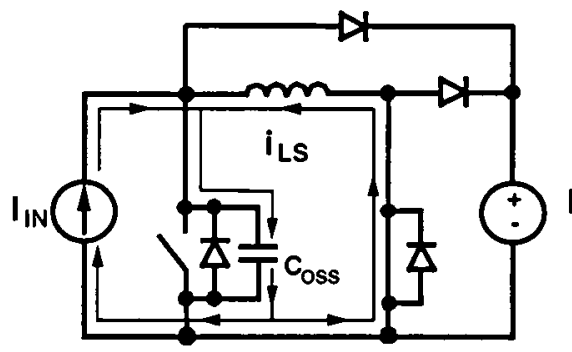

(f) $\left[T_{5}-T_{6}\right]$

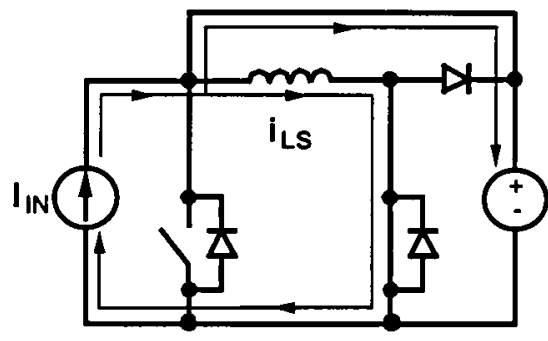

(g) $\left[T_{6}-T_{7}\right]$

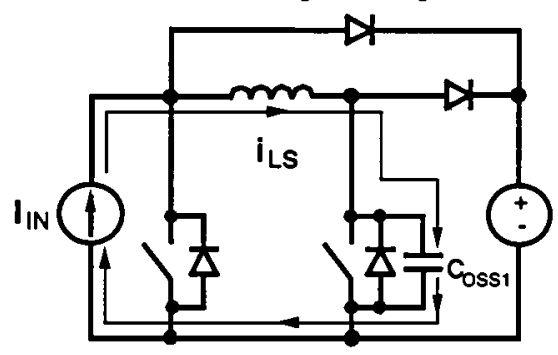

(h) $\left[T_{7}-T_{8}\right]$

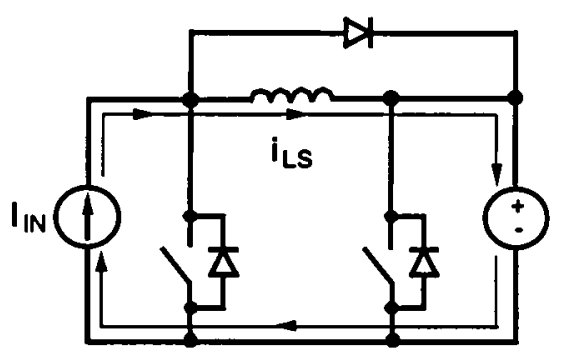

(i) $\left[T_{8}-T_{9}\right]$

Fig. 3. Topological stages of the proposed boost power stage.

$V_{O}$, boost rectifier $D$ becomes forward bias, and $i_{L S}=I_{I N}$ is commutated from $C_{O S S 1}$ to rectifier $D$, as shown in Fig. 3(i). $I_{I N}$ continues to flow through $D$ until a new switching cycle is initiated by turning on switch $S$ at $t=T_{9}$.

\section{DESIGN GUIDELINES}

Generally, the design of the proposed boost converter with the active snubber follows the well-established design rules for the conventional boost power stage since for a properly designed converter with the active snubber the effect of the snubber circuit on the operation and conversion characteristic of the boost power stage is negligible. Specifically, if the commutation time of boost-inductor current $I_{I N}$ from boost rectifier $D$ to boost switch $S$, i.e., time interval $T_{3}-T_{0}$ shown in Fig. 4, is short compared to a switching period, the snubber circuit has no significant effect on the operation of the boost power stage. Otherwise, the conversion-ratio of the boost power stage becomes strongly dependent on the load current, as described in [7].

To reduce the recovered charge of today's fast-recovery rectifiers, it is necessary to reduce their turn-off $d i / d t$ rate to approximately below $100 \mathrm{~A} / \mu \mathrm{S}[1]$. Generally, reducing the $d i / d t$ rate much below $100 \mathrm{~A} / \mu \mathrm{S}$ does not decrease the recovered charge significantly. Therefore, to keep the di/dt rate below $100 \mathrm{~A} / \mu \mathrm{S}$ for a typical output voltage of $V_{O}=400 \mathrm{~V}$, the minimum required $L_{S}$ is $400 \mathrm{~V} / 100 \mathrm{~A} / \mu \mathrm{s}=4 \mu \mathrm{H}$. In fact, for the optimal performance of the majority of today's fast-recovery rectifiers, a snubber inductance in the $4-\mu \mathrm{H}$ to $6-\mu \mathrm{H}$ range seems to be the best choice.

It should be noted that for snubber inductance $L_{S}$ in the $4-\mu \mathrm{H}$ to 6- $\mu \mathrm{H}$ range, the commutation time $T_{3}-T_{0}$ of the boost current is extremely short. For example, for a $1-\mathrm{kW}(400 \mathrm{~V} / 2.5 \mathrm{~A})$ boost power stage operating from an input voltage of $V_{I N}=90$ $\mathrm{V}$, commutation time $T_{3}-T_{0} \sim T_{1}-T_{0}=I_{I N} L_{S} / V_{O}=$ $I_{O} L_{S} / V_{I N}=(2.5 A)(4.7 \mu \mathrm{H}) /(90 \mathrm{~V})=0.13 \mu \mathrm{s}$. This commutation time is approximately 77 times shorter than the switching period of $10 \mu \mathrm{s}$ which corresponds to the $100 \mathrm{kHz}$ switching frequency that is a reasonable choice at this power level.

Since the maximum current and maximum voltage of all semiconductors in the proposed circuit are limited to maximum (low-line) input current $I_{I N(\max )}$ and output voltage $V_{O}$, respectively, the current and voltage rating of the switches and rectifiers should be selected following the same derating rules as for the conventional boost converter. However, it should be noted that the rms current of auxiliary switch $S_{1}$ and snubber rectifier $D_{S}$ are much lower than the rms current of boost switch $S$ and rectifier $D$. As a result, the required power ratings of switch $S_{1}$ and rectifier $D_{S}$ are lower than those of switch $S$ and rectifier $D$. 


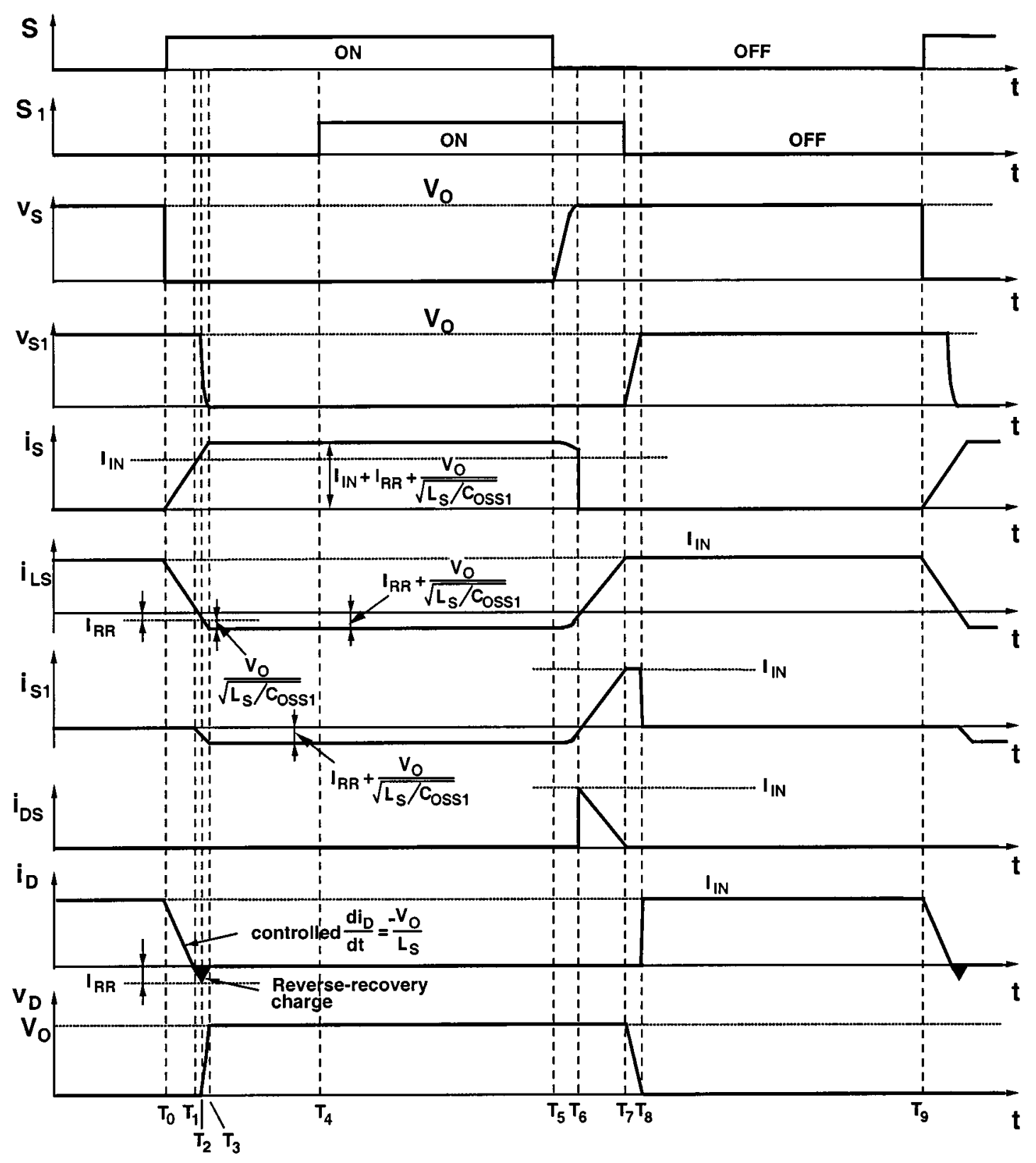

Fig. 4. Key waveforms of the proposed boost power stage.

To maximize the conversion efficiency, a proper timing of the auxiliary-switch gate drive is critical. Generally, to achieve zero-voltage switching, auxiliary switch $S_{1}$ should be turned on after main switch $S$ is turned on and while its body diode $D_{A P 1}$ is conducting. Because of a long conduction interval of $D_{A P 1}$, the turn-on timing of $S_{1}$ is not a problem. However, the turn-off timing of $S_{1}$ requires more attention. Namely, if auxiliary switch $S_{1}$ stays closed much longer after $i_{D S}$ reaches zero at $t=T_{7}$, the output capacitance of switch $S, C_{O S S}$, the junction capacitance of snubber rectifier $D_{S}, C_{J S}$, and snubber inductor $L_{S}$ will resonate. This resonance increases snubber inductor current $i_{L S}$ above $I_{I N}$ so that when $S_{1}$ is eventually turned off, snubber rectifier $D_{S}$ ends up carrying the current in excess of $I_{I N}$ that is created by the resonance, whereas rectifier $D$ carries current $I_{I N}$. As a result, when boost switch $S$ is turned on, snubber rectifier $D_{S}$ introduces reverse-recovery losses since the anode of $D_{S}$ is directly connected to switch $S$. Because the current flowing trough $D_{S}$ is generally small, the reverse-recovery-related losses due to a "hard" turn-off of $D_{S}$ are relatively small. Nevertheless, to maximize the efficiency this loss should be minimized. Therefore, for an optimally designed converter, the fixed time interval between the turn-off of main switch $S$ and the turn-off of auxiliary switch $S_{1}$ should be adjusted so that at low line and full load switch $S_{1}$ is turned off at the moment current $i_{D S}$ reaches zero. Although for such an adjustment of the gate-drive signals current iDS is not zero at the moment $S_{1}$ is turned off at other line and load conditions, $i_{D S}$ is still small enough so it does not introduce significant reverse-recovery related losses.

Finally, it should be also noted that the control of the proposed boost converter could be implemented in the same way as in its conventional "hard" switched counterpart as long as 

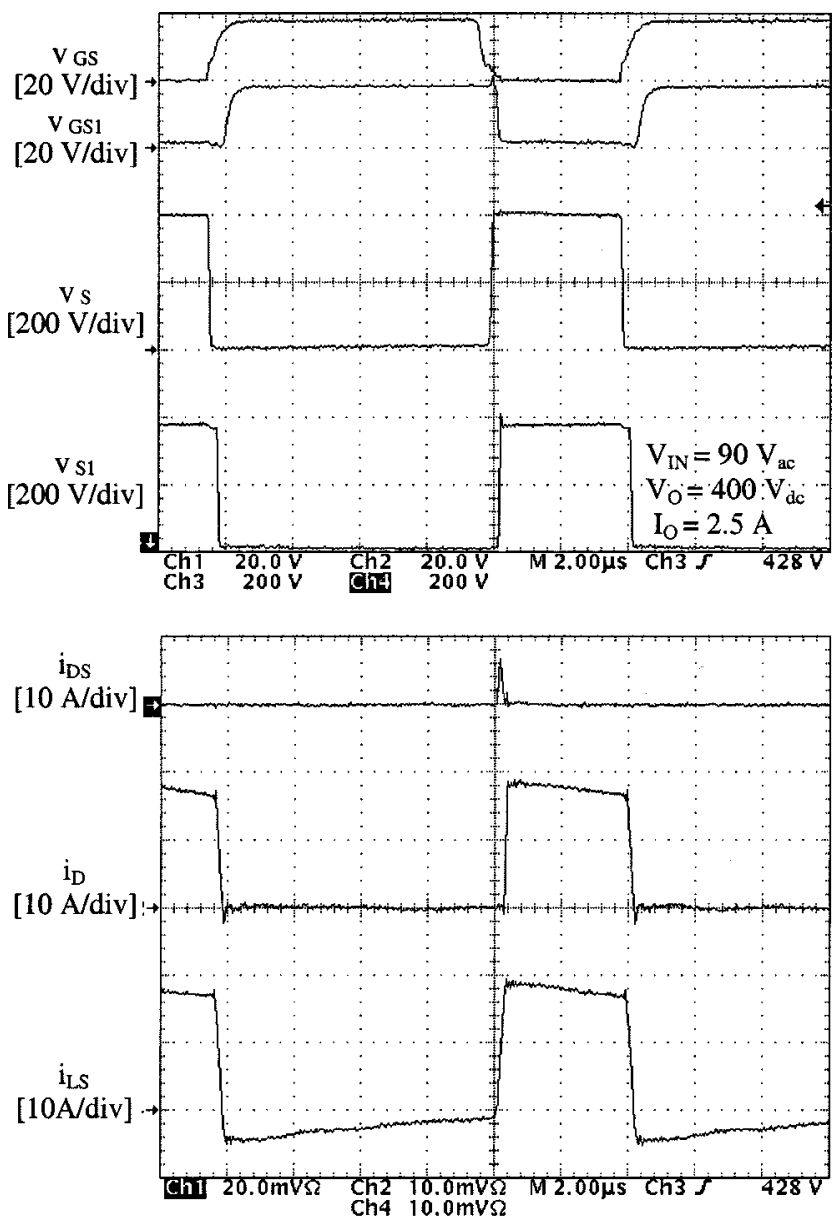

Fig. 5. Measured key waveforms of experimental converter at $P_{O}=1 \mathrm{~kW}$ and $V_{I N}=90 \mathrm{~V}_{\mathrm{ac}}$. Time base: $2 \mu \mathrm{s} / \mathrm{div}$.

an additional gate-driver circuit is provided. Specifically, in the input-current-shaping applications, the proposed converter can be implemented with any known control technique, such as average current, peak current, or hysteretic control.

\section{EXPERIMENTAL RESULTS}

The performance of the boost converter with the proposed active snubber was evaluated on a $1-\mathrm{kW}(400 \mathrm{~V} / 2.5 \mathrm{~A})$, universal-line-range (90-265 $\mathrm{V}_{\mathrm{ac}}$ ) power-factor-correction circuit operating at $80 \mathrm{kHz}$. For comparison purposes, the experimental circuit was implemented using both an IGBT and a MOSFET for main switch $S$. The other components in both experimental implementations were the same. The experimental circuit were implemented using the following components: boost switch $S$-IXGK50N60B (IGBT implementation), IXFK48N50 (MOSFET implementation); auxiliary switch $S_{1}-2$ SK2837 (MOSFET); boost rectifier $D$ - two RHRP3060 connected in parallel; boost inductor $L=0.8 \mathrm{mH}$; snubber inductor $L_{S}=$ $4.7 \mu \mathrm{H}$; snubber rectifier $D_{S}-\mathrm{RHRP} 3060$, and bulk capacitor $C_{F}=$ two $470 \mu \mathrm{F} / 450 \mathrm{~V}$ connected in parallel.

Boost inductor $L$ was built using Magnetics toroidal core (Kool $\mathrm{Mu}$ 77439-A7, two cores in parallel) and 55 turns of AWG\#14, whereas snubber inductor $L_{S}$ was built with Magnetics toroidal core (Kool Mu 77932-A7) with 12 turns of
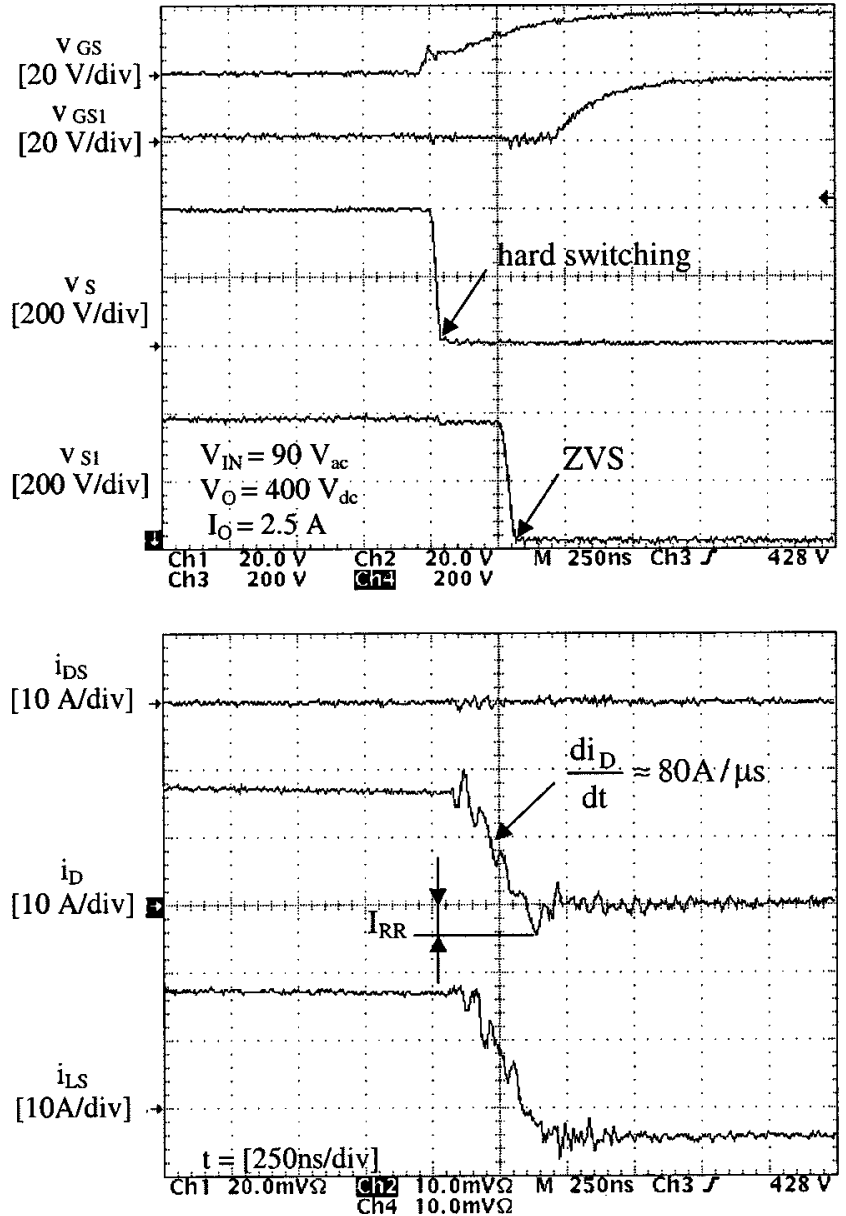

Fig. 6. Detailed view of key waveforms shown in Fig. 5 during turn-on transition. Time base: $250 \mathrm{~ns} /$ div.

AWG\#14. With the selection of $L_{S}=4.7 \mu \mathrm{H}$, the $d i / d t$ turn-off rate of the rectifier was limited to $d i_{D} / d t=V_{O} / L_{S}=80 \mathrm{~A} / \mu \mathrm{s}$. The control circuit was implemented with the average-current PFC controller UC3854. The TC4420 and TSC428 drivers were used to generate the required gate-drive signals for the main and auxiliary switches, respectively.

Fig. 5 shows the oscillograms of key waveforms of the IGBT implementation of the experimental converter at the low line and full power. As can be seen comparing corresponding waveforms in Figs. 4 and Fig. 5, there is a good agreement between the experimental and theoretical waveforms. The more detailed oscillograms of the key waveforms in Fig. 5 around the turn-on and turn-off transition of the boost switch are shown in Figs. 6 and 7, respectively. As can be seen from Fig. 6, auxiliary switch $S_{1}$ is turned on with ZVS since its voltage $V_{S 1}$ falls to zero before gate-drive signal $V_{G S 1}$ becomes high. However, boost switch $S$ is "hard" switched, i.e., $S$ is turned on while voltage across it $v_{S}=V_{O}=400 \mathrm{~V}$. Despite the "hard" switching of boost switch $S$, all waveforms are ringing free. Also, it should be noted that the boost-rectifier-current turn-off rate, which is controlled by $L_{S}$, is approximately $d i_{D} / d t=80 \mathrm{~A} / \mu \mathrm{s}$, as indicated in Fig. 6 . With this $d i_{D} / d t$ rate, peak reverse-recovery current $I_{R R}$ is reduced to approximately $4 \mathrm{~A}$, which corresponds to a recovered charge of approximately $100 \mathrm{nC}$. Finally, as shown in Fig. 7, the 

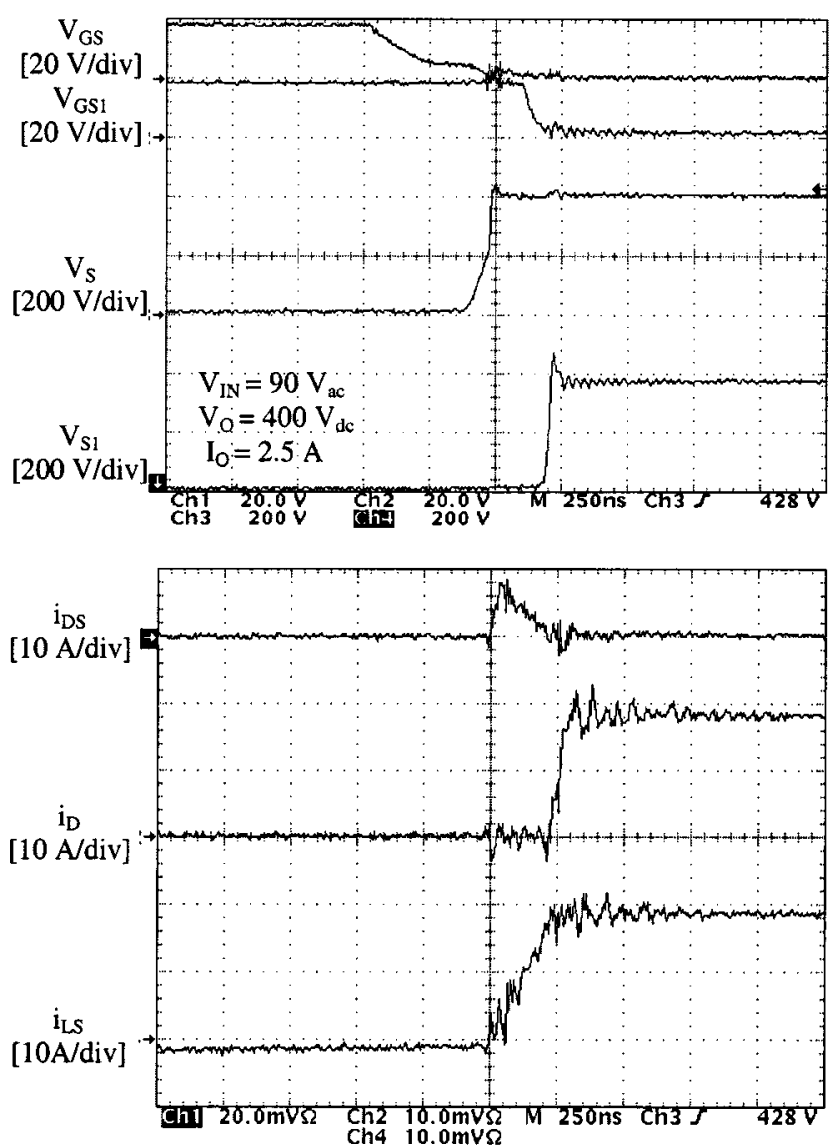

Fig. 7. Detailed view of key waveforms shown in Fig. 5 during turn-off transition. Time base: $250 \mathrm{~ns} / \mathrm{div}$.

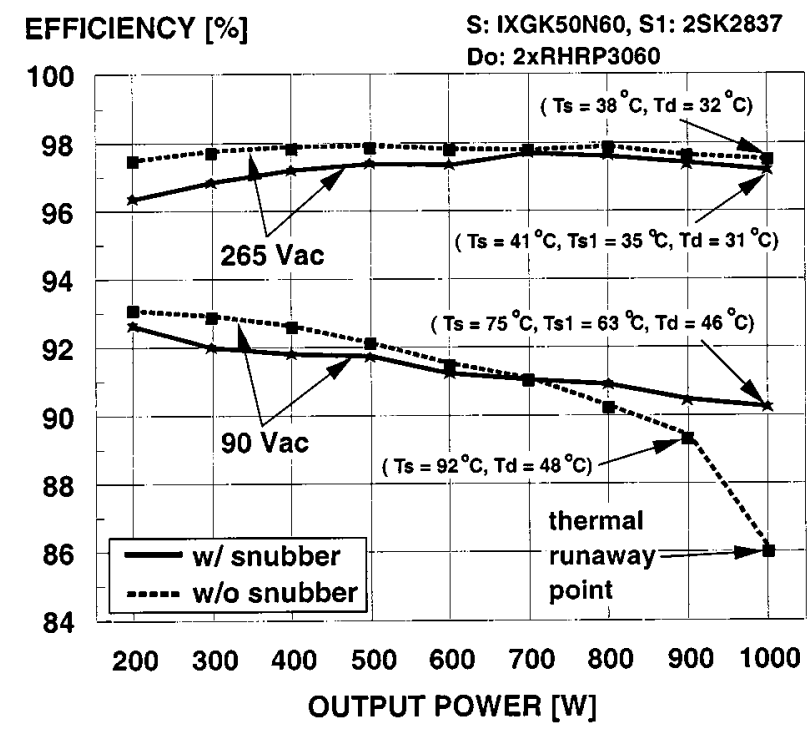

Fig. 8. Measured efficiency of 1-kW experimental circuit implemented with IGBT boost switch.

voltage across boost switch $S$ is well clamped by $D_{S}$ during the switch $S$ turn-off.

Fig. 8 shows the measured efficiencies of the IGBT implementation of the experimental converter with and without the active snubber at the minimum and maximum line voltage as

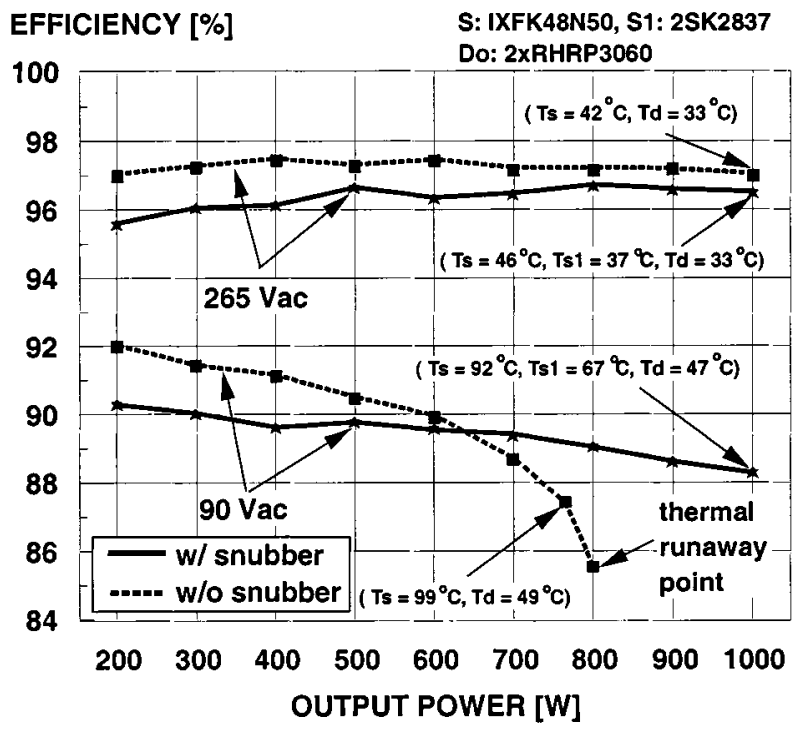

Fig. 9. Measured efficiency of 1-kW experimental circuit implemented with MOSFET boost switch.

functions of the output power. As can be seen from Fig. 8, at the high line $\left(265 \mathrm{~V}_{\mathrm{ac}}\right)$, the efficiency of the converter with the active snubber is slightly lower than the efficiency of the implementation without the snubber. In fact, at the high line the loss of the added active snubber circuit is larger than the reduction of the reverse-recovery-related losses of the converter without the snubber because at the high line the rectifier current and, therefore, reverse-recovery losses are relatively small. Also, at the low line $\left(90 \mathrm{~V}_{\mathrm{ac}}\right)$, the efficiency of the circuit with and without snubber is almost the same up to the 700-W level. However, for power levels higher than $700 \mathrm{~W}$, where reverse-recovery losses are substantially increased, the active-snubber improves the efficiency significantly. In fact, the maximum power that can be obtained from the circuit without the snubber is limited to around $900 \mathrm{~W}$ due to the thermal runaway of the boost diode caused by excessive reverse-recovery losses. With the snubber, the circuit can deliver the full power of $1 \mathrm{~kW}$ with the temperature of the semiconductors well within the acceptable levels, as shown in Fig. 8.

Fig. 9 shows the measured efficiencies of the MOSFET implementation of the experimental converter with and without the active snubber at the minimum and maximum line voltages as functions of the output power. The efficiencies of the circuit with and without the snubber show a similar general trend as for the IGBT implementation, i.e., the active snubber improves the low-line efficiency at higher output power levels where the reverse-recovery losses are significant. As can be seen from Fig. 9, without the snubber, the experimental circuit could not deliver more than approximately $750 \mathrm{~W}$ because of the boost diode thermal runaway. With the snubber, the circuit was able to deliver the full power of $1 \mathrm{~kW}$.

Finally, it should be noted that in the above experimental efficiency evaluations, the emphasis was on the relative efficiency comparisons between implementations with and without the snubber. No attempt was made to maximize the absolute efficiency of the experimental circuit for any implementation by selecting less lossy semiconductor or passive components. 


\section{CONCLUSION}

A minimum-component-count active snubber which improves the performance of high-power boost converters by reducing the reverse-recovery-related losses is described. The snubber consists of a snubber inductor, rectifier, and a ground-referenced (directly) driven auxiliary switch. The voltage and current stresses of the components in the proposed active-snubber boost converter are similar to those in its conventional "hard-switched" counterpart. It was experimentally verified on a $1-\mathrm{kW}$, universal-input, boost-power-stage prototype that the proposed active snubber is effective in extending the power range of the boost converter by reducing the reverse-recovery-related losses.

\section{REFERENCES}

[1] Y. Khersonsky, M. Robinson, and D. Gutierrez, "New fast recovery diode technology cuts circuit losses, improves reliability," Power Conversion Intell. Motion (PCIM) Mag., pp. 16-25, May 1992.

[2] R. Streit and D. Tollik, "High efficiency telecom rectifier using a novel soft-switched boost-based input current shaper," in Proc. Int. Telecommun. Energy Conf. (INTELEC), Oct. 1991, pp. 720-726.

[3] G. Hua, C. S. Leu, and F. C. Lee, "Novel zero-voltage-transition PWM converters," in Proc. IEEE Power Electron. Spec. Conf. (PESC) Rec., June 1992, pp. 55-61.

[4] D. C. Martins, F. J. M. de Seixas, J. A. Brilhante, and I. Barbi, "A family of dc-to-dc PWM converters using a new ZVS commutation cell," in Proc. IEEE Power Electron. Spec. Conf. (PESC) Rec., June 1993, pp. 524-530.

[5] J. Bassett, "New, zero voltage switching, high frequency boost converter topology for power factor correction," in Proc. Int. Telecommun. Energy Conf. (INTELEC), Oct. 1995, pp. 813-820.

[6] M. M. Jovanović, "A technique for reducing rectifiere reverse-recoveryrelated losses in high-voltage, high-power boost converters," in Proc. IEEE Appl. Power Electron. (APEC) Conf., Mar. 1997, pp. 1000-1007.

[7] C. M. C. Duarte and I. Barbi, "An improved faily of ZVS-PWM active-clamping dc-to-dc converters," in Proc. IEEE Power Electron. Spec. Conf. (PESC) Rec., May 1998, pp. 669-675.

[8] G. Carli, "Harmonic distortion reduction schemes for a new 100A-48 V poer supply," in Proc. Int. Telecommun. Energy Conf. (INTELEC), 1992, pp. 524-531.
[9] K. Smith and K. M. Smedley, "Lossless, passive soft switching methods for inverters and amplifiers," in IEEE Power Electron. Spec. Conf. (PESC) Rec., 1997, pp. 1431-1439.

[10] C. J. Tseng and C. L. Chen, "Passive lossless snubbers for dc/dc converters," in Proc. IEEE Appl. Power Electron. Conf. (APEC), 1998, pp. 1049-1054.

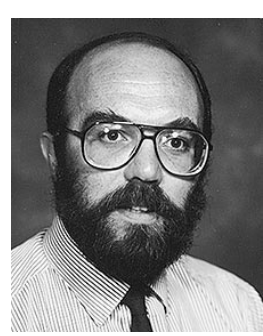

Milan M. Jovanovic (S'86-M'89-SM'89) was born in Belgrade, Yugoslavia. He received the Dipl.-Ing. degree in electrical engineering from the University of Belgrade, Yugoslavia, the M.S.E.E. degree from the University of Novi Sad, Yugoslavia, and the $\mathrm{Ph} . \mathrm{D}$. degree in electrical engineering from the Virginia Polytechnic Institute and State University (Virginia Tech), Blacksburg.

He is the Vice President for Research and Development of Delta Products Corporation, Research Triangle Park, NC (U.S. subsidiary of Delta Electronics, Inc., Taiwan, R.O.C., one of the world's largest manufacturers of power supplies). His 23-year experience includes the analysis and design of high-frequency, high-power-density power processors; modeling, testing, evaluation, and application of high-power semiconductor devices; analysis and design of magnetic devices; and modeling, analysis, and design of analog electronics circuits. His current research is focused on power conversion and management issues for portable data-processing equipment, design optimization methods for low-voltage power supplies, distributed power systems, and power-factor-correction techniques.

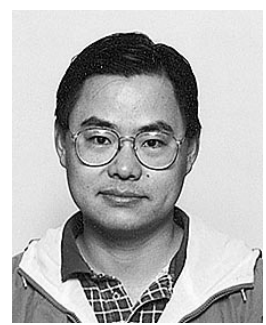

Yungtaek Jang (S'92-M'95) was born in Seoul, Korea. He received the B.S. degree from Yonsei University, Seoul, Korea, in 1982, and the M.S. and Ph.D. degrees from the University of Colorado, Boulder, in 1991 and 1995, respectively, all in electrical engineering.

From 1982 to 1988, he was a Design Engineer with Hyundai Engineering Co., Seoul. From 1995 to 1996 , he was a Senior Engineer with Advanced Energy Industries, Inc., Fort Collins, CO. Since 1996, he has been a Project Engineer with the Power Electronics Laboratory, Delta Products Corporation, Research Triangle Park, NC. His research interests include resonant power conversion, converter modeling, control techniques, and low harmonic rectification. 